\title{
Electron Transfer in Supercritical Carbon Dioxide: Ultraexothermic Charge Recombination at the End of the "Inverted Region"
}

\author{
Carlos Serpa, Paulo J. S. Gomes, Luis G. Arnaut,* Sebastião J. Formosinho, \\ João Pina, and J. Seixas de Melo ${ }^{[a]}$
}

\begin{abstract}
Charge-recombination rates in contact radical-ion pairs, formed between aromatic hydrocarbons and nitriles in supercritical $\mathrm{CO}_{2}$ and heptane, decrease with the exothermicity of the reactions until they reach $-70 \mathrm{kcal} \mathrm{mol}^{-1}$, but from there on an increase is observed. The first decrease in rate is typical of the "inverted
\end{abstract}

region" of electron-transfer reactions. The change to an increase in the rate for ultra-exothermic electron transfer indicates a new free-energy relation-

Keywords: calorimetry - electron transfer $\cdot$ fluorescence $\cdot$ ion pairs • supercritical fluids ship. We show that the resulting "double-inverted region" is not due to a change in mechanism. It is an intrinsic property of electron-transfer reactions, and it is due to the increase of the reorganisation energy with the reaction exothermicity.

\section{Introduction}

Charge-separated states are very important intermediates in many photoinduced reactions. ${ }^{[1,2]}$ They result from chargetransfer interactions between an electron donor (D) and an acceptor (A), with one of them in an excited state. Such states may carry a significant fraction of the light energy initially absorbed and controlling their decay has become a major endeavour in solar-energy conversion, light-emitting devices, nanoelectronics and other important emerging technologies. ${ }^{[3-5]}$ The paradigm of this field is that very exothermic charge recombinations (CR) occur in the Marcus "inverted region" ${ }^{[6]}$ that is, the rate decreases with increasing reaction exothermicity. The most exothermic charge recombination should yield the longest lived charge-separated state for an identical donor-acceptor distance.

Charge-separated states produced by bimolecular reactions are usually regarded as radical ion pairs or exciplexes, depending on the degree of charge separation. Scheme 1 illustrates the decay mechanisms when exciplexes are formed by photoinduced charge separation: radiative decay $\left(k_{\mathrm{F}}\right)$, intersystem crossing $\left(k_{\text {isc }}\right)$, photoreaction $\left(k_{\mathrm{r}}\right)$ and charge re-

[a] Dr. C. Serpa, P. J. S. Gomes, Prof. L. G. Arnaut,

Prof. S. J. Formosinho, J. Pina, Dr. J. S. de Melo

Departamento de Química, Universidade de Coimbra

3004-535 Coimbra (Portugal)

Fax: $(+351) 239-827-703$

E-mail: lgarnaut@ci.uc.pt

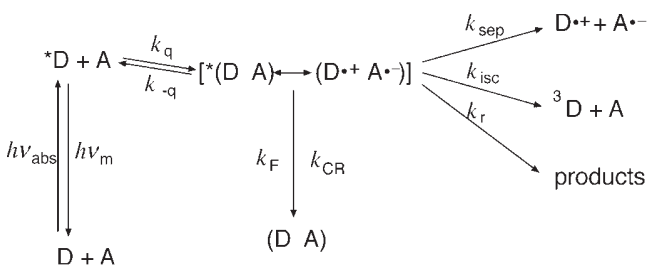

Scheme 1. Mechanism for photoinduced charge separation and charge recombination in weakly polar solvents.

combination $\left(k_{\mathrm{CR}}\right)$. The solvation of the charge-separated state leading to production of free ions $\left(k_{\text {sep }}\right)$ is thermodynamically unfavourable in weakly polar solvents.

Our main motivation is to provide experimental data on ultraexothermic $\left(\Delta G^{0}<-60 \mathrm{kcalmol}^{-1}\right)$ charge-recombination rates that help to identify the factors that control these rates. The electron donors selected for this study, illustrated in Scheme 2 together with their oxidation potentials, ${ }^{[7]}$ were selected for their structural homogeneity, allowing us to focus on the role played by the reaction energy in the reactivity of the charge-separated states. Additionally, we employed only one electron acceptor, fumaronitrile (FN) $\left(E_{\mathrm{A}}^{\mathrm{red}}=-1.36 \mathrm{eV}\right.$ versus SCE $){ }^{[8]}$ The choice of these systems was also guided by early work on fumaronitrile/aromatic hydrocarbons in benzene which showed that they form exciplexes with nanosecond lifetimes. ${ }^{[9-11]}$

In this work we show that photoinduced charge separation from aromatic hydrocarbons to nitriles in supercritical 


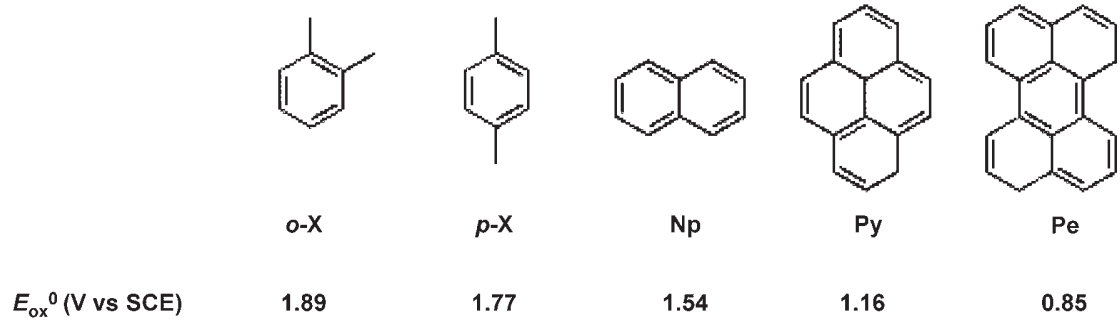

Scheme 2. Electron donors and their oxidation potentials $(o-\mathrm{X}=o$-xylene; $p-\mathrm{X}=p$-xylene; $\mathrm{Np}=$ naphthalene $\mathrm{Py}=$ pyrene; $\mathrm{Pe}=$ perlene).

$\mathrm{CO}_{2}\left(\mathrm{scCO}_{2}\right)$ leads to exciplexes with nearly complete charge separation. The weak fluorescence of the charge-separated species is a convenient parameter to measure their lifetimes. The study of such exothermic charge recombination $(\mathrm{CR})$ in $\mathrm{scCO}_{2}$ addresses a fundamental controversy in the field of electron-transfer reactions: the relatively weak driving-force dependence of the rates in the inverted region. Does it reflect the "weak-coupling" limit of a radiationless transition, with negligible solvent reorganisation, as suggested by Mataga and co-workers $?^{[12,13]}$ Can it be interpreted with the conventional nonadiabatic theories, by using reorganisation energies and electronic couplings that vary with the structure of the molecular species, as proposed by Gould and Farid ? $^{[14]}$ Does it result from the increase in reorganisation energy with the reaction energy as predicted by the intersecting-state model (ISM) ? ${ }^{[15,16]}$

\section{Results}

The absorption of light by an aromatic hydrocarbon in $\mathrm{scCO}_{2}$ very rapidly leads to a fluorescent singlet-excited state. This state can be subsequently quenched by fumaronitrile (FN) and, when the thermodynamics of the process is favourable, leads to a charge-separated species, Scheme 1. Figure 1 illustrates the quenching of $p$-xylene fluorescence by increasing amounts of fumaronitrile in $\mathrm{scCO}_{2}$, and the concomitant growth of the exciplex emission. Similar results

\footnotetext{
Abstract in Portuguese: As velocidades de recombinação de carga em pares iónicos de contacto formados entre hidrocarbonetos aromáticos e nitrilos em $\mathrm{CO}_{2}$ supercrítico e em heptano, diminuem com o aumento da exotermicidade das reacções até esta atingir -70 $\mathrm{kcalmol}^{-1}$, a partir da qual se observa a tendência contrária. A primeira diminuição é típica da "região invertida" das reacções de transferência de electrão. A mudança para um aumento das velocidades em reacções de transferência de electrão ultra-exotérmicas revela uma nova relação de energia livre. Demonstra-se que a "dupla região invertida" observada não se deve a uma mudança de mecanismo. Ela é uma propriedade intrínseca das reacções de transferência de electrão, e é devida ao aumento da energia de reorganização com a exotermicidade da reacção.
}

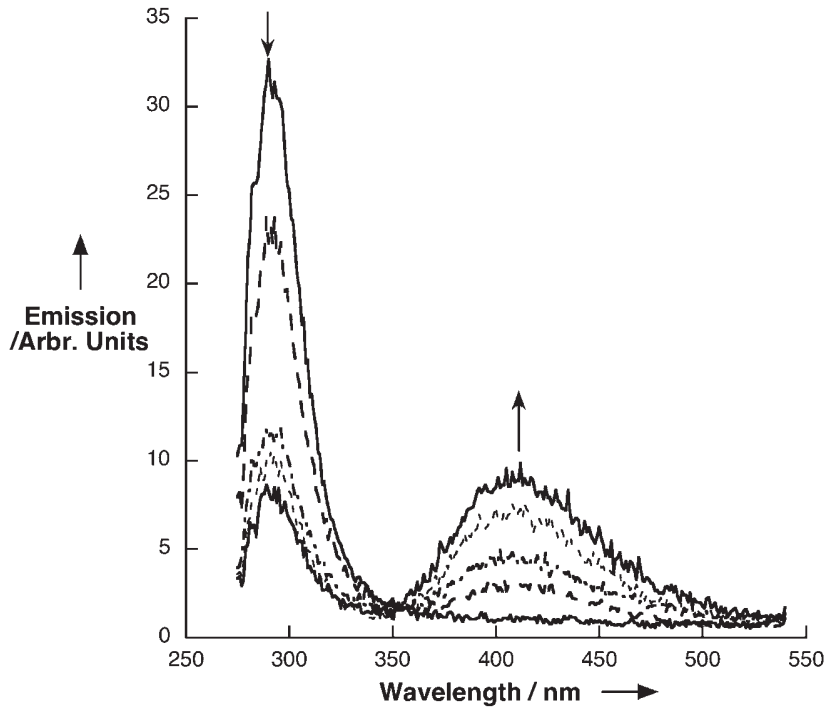

Figure 1. Steady-state fluorescence emission of $p$-xylene with increasing amounts of fumaronitrile, in supercritical $\mathrm{CO}_{2}$ at $308 \mathrm{~K}$ and $11 \mathrm{MPa}$, excited at $273 \mathrm{~nm} .[p-\mathrm{X}]=0.91 \mathrm{~mm}$, [fumaronitrile] $=0,1.0,1.5,2.0$, 2.8, $4.0 \mathrm{~mm}$.

tion of the corresponding monomer $\left(\tilde{v}_{\mathrm{m}}\right) \cdot{ }^{[18]}$

According to the Lippert-Mataga relationship, ${ }^{[19,20]} \tilde{\nu}_{\text {ex }}$ is determined by the dipole moment of the exciplex $(\mu)$ in a solvent of dielectric constant $\varepsilon$ and refractive index $n$ [Eq. (1)].

$\tilde{v}_{\mathrm{ex}}=\tilde{v}_{\mathrm{ex}}(0)-\frac{2 \mu^{2}}{h c \rho^{3}}\left(f_{\varepsilon}-\frac{1}{2} f_{n}\right)$

In Equation (1) $\tilde{v}_{\text {ex }}(0)$ is the exciplex emission maximum in the gas phase, $f_{\varepsilon}=(\varepsilon-1) /(2 \varepsilon+1), f_{n}=\left(n^{2}-1\right) /\left(2 n^{2}+1\right)$, and $\rho$ is the radius of the sphere representing the exciplex. A full charge separation across a $3.32 \AA$ distance, observed for the pyrene/tetracyanoethylene complex, ${ }^{[21,22]}$ should yield $\mu=16 \mathrm{D}$. The slopes of the Lippert-Mataga plots measured in this work together with a cavity radius $\rho=5 \AA \AA^{[18,23]}$ supported by molecular models, ${ }^{[24]}$ give the dipole moments presented in Table 1; these values average the dipole moment of a full charge separation.

We confirmed the values of $\rho$ using Connolly surfaces. ${ }^{[25,26]}$ First, we optimised the structure of the molecules using the AM1 method. Then, donor and acceptor were placed at a 
Table 1. Emission frequencies and charge recombination energies in supercritical $\mathrm{CO}_{2}$ at $308 \mathrm{~K}$ and $15 \mathrm{MPa}$, and dipole moments of the exciplexes in liquid solvents. ${ }^{[a]}$

\begin{tabular}{lllll}
\hline & $\tilde{v}_{\mathrm{m}} / 1000\left[\mathrm{~cm}^{-1}\right]$ & $\tilde{v}_{\mathrm{ex}} / 1000\left[\mathrm{~cm}^{-1}\right]$ & $\Delta G_{\mathrm{CR}}^{0}\left[\mathrm{kcalmol}^{-1}\right]$ & $\mu[\mathrm{D}]$ \\
\hline $\mathrm{Pe}+\mathrm{FN}$ & 23.42 & {$[\mathrm{~b}]$} & -62.0 & - \\
$\mathrm{Py}+\mathrm{FN}$ & 27.03 & 21.05 & -69.1 & 19 \\
$\mathrm{~Np}+\mathrm{FN}$ & 31.45 & 22.73 & -77.9 & 17 \\
$p-\mathrm{X}+\mathrm{FN}$ & 34.48 & 24.39 & -83.2 & 14 \\
$o-\mathrm{X}+\mathrm{FN}$ & 34.48 & 24.51 & -86.0 & 13 \\
\hline
\end{tabular}

[a] $\Delta G_{\mathrm{CR}}^{0}$ is the negative value of the exciplex free energy [Eq. (2)] with a $-2.5 \mathrm{kcalmol}^{-1}$ correction. The oxidation potentials given in Scheme 2 and $E_{\mathrm{A}}^{\mathrm{red}}=-1.36 \mathrm{eV}$ versus SCE for fumaronitrile were used in this calculation. ${ }^{[7,8]}[\mathrm{b}]$ The exciplex emission overlaps with the tail of the perylene emission.

$3.32 \AA$ interplanar distance. Next, the surface of the exciplex was calculated with a probe with a $1.4 \AA$ radius, and its contact-re-entrant volume was calculated. Figure 2 shows some

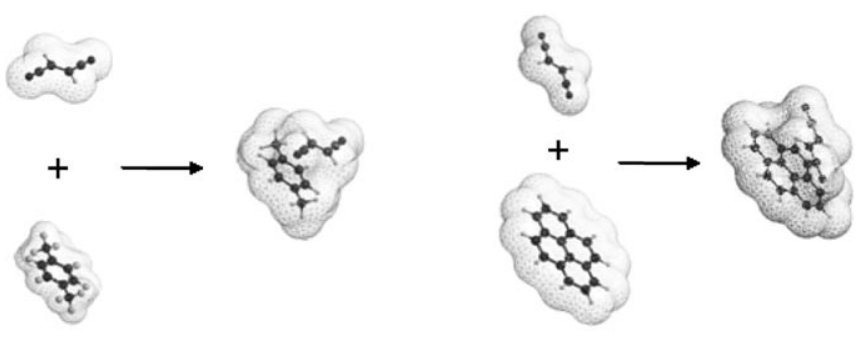

Figure 2. Connolly surfaces for the exciplex formation between fumaronitrile and $p$-xylene or pyrene.

of the objects obtained. The radii of spheres with the same volume as these objects range from $4.0 \AA$ for xylene/fumaronitrile to $4.6 \AA$ for perylene/fumaronitrile, and should be regarded as lower limits to the physical systems, because the interplanar separation is also a lower limit. Thus, the dipole moments reported in Table 1 should be considered reliable values.

Gould and co-workers showed that when $\left(\tilde{v}_{\mathrm{m}}-\tilde{v}_{\mathrm{ex}}\right)>$ $5000 \mathrm{~cm}^{-1}$, the charge separation in the exciplex is nearly complete. ${ }^{[18]}$ The $\tilde{v}_{\mathrm{m}}$ and $\tilde{\nu}_{\mathrm{ex}}$ values reported in Table 1 further confirm that the exciplexes formed in $\mathrm{scCO}_{2}$ can be regarded as essentially pure contact radical-ion pairs (CRIP), $\mathrm{A}^{\cdot-} \mathrm{D}^{\cdot+}$.

The free energy of exciplex formation has been studied in detail by several authors. ${ }^{[27,28]}$ According to the semiempirical equation of Weller, ${ }^{[27]}$ the exciplex free energy is given, in $\mathrm{eV}$, by Equation (2), in which $E_{\mathrm{D}}^{\mathrm{ox}}$ and $E_{\mathrm{A}}^{\mathrm{red}}$ are the oxidation and reduction potentials of donor and acceptor, respectively, measured in the same polar solvent, and $\mu^{2} / \rho^{3}=$ $0.75 \mathrm{eV}^{[27]}$

$\Delta G_{\mathrm{ex}}^{0}=E_{\mathrm{D}}^{\mathrm{ox}}-E_{\mathrm{A}}^{\mathrm{red}}-\frac{\mu^{2}}{\rho^{3}}\left(f_{\varepsilon}-f_{n}\right)+0.38$

According to this equation, the energies of our chargeseparated species are $6-22 \mathrm{kcal} \mathrm{mol}^{-1}$ lower than the corre- sponding singlet-excited-state energies, and the charge separation is irreversible $\left(k_{\mathrm{q}} \gg k_{-\mathrm{q}}\right)$. On the other hand, 1,4-dicyanobenzene and toluene form a reversible exciplex in weakly polar solvents, ${ }^{[29]}$ and the ratio between the rate constant of exciplex formation $\left(k_{\mathrm{q}}\right)$ and that of dissociation $\left(k_{-\mathrm{q}}\right)$ suggests that exciplex formation can be as much as $5 \mathrm{kcal} \mathrm{mol}^{-1}$ less exothermic than that predicted by Weller's equation. Additionally, the spectral fitting of the hexamethylbenzene/tetracyanoethylene (HMB/TCNE) chargetransfer complex in $\mathrm{scCO}_{2}$ also suggests that the formation of this complex is $6 \mathrm{kcalmol}^{-1}$ less exothermic than predicted by Equation (2). ${ }^{[30]} \mathrm{We}$ added a $-2.5 \mathrm{kcal} \mathrm{mol}^{-1}$ correction to the $\mathrm{CR}$ reaction energies calculated with Equation (2), and report them in Table 1 . In addition we added a $2.5 \mathrm{kcal} \mathrm{mol}^{-1}$ correction to the $\mathrm{CR}$ reaction energies obtained by spectral fitting. With such corrections, the CR energies obtained by three different methods are self-consistent, but should be regarded as having a $2.5 \mathrm{kcal} \mathrm{mol}^{-1}$ uncertainty.

Table 2 reports the lifetimes of the charge-separated species in $\mathrm{scCO}_{2}, n$-heptane and tetrahydrofuran (THF) measured by time-correlated single-photon counting (TCSPC).

Table 2. Lifetimes [ns] of charge-separated states, measured in $n$-heptane and THF at $298 \mathrm{~K}$, and in supercritical $\mathrm{CO}_{2}$ at $308 \mathrm{~K}$ and $15 \mathrm{MPa}$. ${ }^{[a]}$

\begin{tabular}{llll}
\hline & $n$-Heptane & $\mathrm{scCO}_{2}$ & Tetrahydrofuran \\
\hline $\mathrm{Pe}+\mathrm{FN}$ & 11.5 & 11.4 & - \\
$\mathrm{Py}+\mathrm{FN}$ & 18.0 & 35.2 & - \\
$\mathrm{Np}+\mathrm{FN}$ & 9.35 & 10.7 & 10.3 \\
$p-\mathrm{X}+\mathrm{FN}$ & 5.1 & 2.1 & - \\
$o-\mathrm{X}+\mathrm{FN}$ & 5.2 & 2.3 & 7.3 \\
$\mathrm{HMB} / \mathrm{TCNE}$ & $0.0112^{[\mathrm{b}]}$ & $0.005^{[\mathrm{c}]}$ & $0.00213^{[\mathrm{b}]}$ \\
\hline
\end{tabular}

[a] Errors are less than 5\%. [b] See reference [36], but cyclohexane rather than heptane was used as solvent. [c] See reference [40].

A typical decay is illustrated in Figure 3. Only two systems revealed sufficiently intense exciplex fluorescence in THF to be characterised, but the trend in their lifetimes is similar to

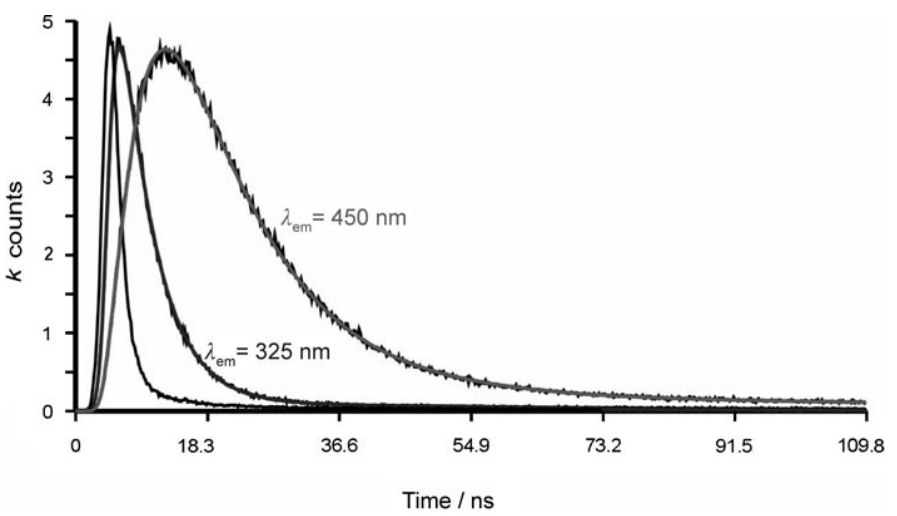

Figure 3. Fluorescence decays of naphthalene in the presence of fumaronitrile, in supercritical $\mathrm{CO}_{2}$ at $308 \mathrm{~K}$ and $15 \mathrm{MPa}$, monitored at $\lambda=$ $325 \mathrm{~nm}$ (monomer) and $\lambda=450 \mathrm{~nm}$ (exciplex). [naphthalene] $=0.25 \mathrm{~mm}$, [fumaronitrile] $=5.2 \mathrm{~mm}$. The shorter decay is the pulse profile of the excitation source. 
that measured in $\mathrm{scCO}_{2}$ and $n$-heptane. The energy of the free ions in THF is expected to be very similar to that of CRIP, as opposed to the less-polar solvents in which dissociation into free-ions is thermodynamically unfavourable. The relative importance of all the processes contributing to the decay of the charge-separated (CS) species in weakly polar solvents can be assessed from the quantum yields of exciplex fluorescence $\left(\Phi_{\mathrm{F}}^{\mathrm{CS}}\right)$, intersystem-crossing $\left(\Phi_{\mathrm{T}}^{\mathrm{CS}}\right)$, and product formation $\left(\Phi_{\mathrm{P}}^{\mathrm{CS}}\right)$. We made this evaluation by studying in detail the role of the radiative and nonradiative decay channels in heptane.

A reasonable estimate for $\Phi_{\mathrm{F}}^{\mathrm{CS}}$ can be obtained by using the following procedure:

1) A Gaussian curve is fitted to the exciplex emission spectrum (in units of $\mathrm{cm}^{-1}$ ), and its area is calculated.

2) The efficiency $\left(\phi_{\mathrm{F}}\right)$ of exciplex emission is obtained as the ratio of this area and that of the pure fluorophore absorbing the same amount of light at the excitation wavelength, multiplied by its fluorescence quantum yield. ${ }^{[31]}$

3) $\Phi_{\mathrm{F}}^{\mathrm{CS}}$ is obtained as ratio between $\phi_{\mathrm{F}}$ and the fraction of monomers that were quenched, given by $\left(I_{0}-I\right) / I$ in which $I_{0}(I)$ is the fluorescence intensity in the absence (presence) of quencher.

Figure 4 presents the fluorescence of perylene in the absence and presence of fumaronitrile in heptane. We chose this system to illustrate the fitting of the exciplex emission

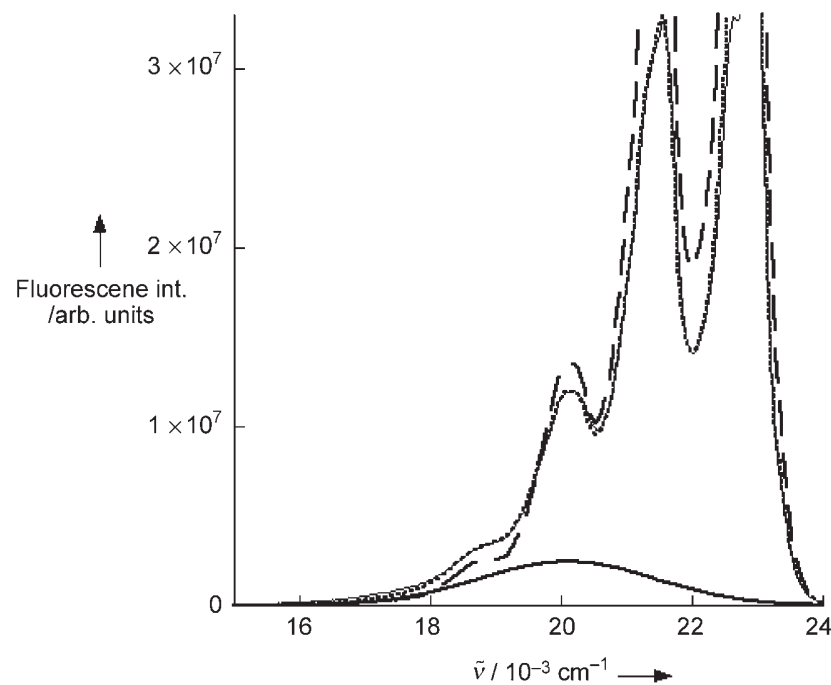

Figure 4. The steady-state fluorescence of perylene (---) and perylene in the presence of fumaronitrile $5.8 \times 10^{-3} \mathrm{M}(\cdots .$.$) in heptane. The thin line$ was obtained as a linear combination of the perylene emission and the Gaussian (-) curve simulating the exciplex emission. because it has the smallest separation between monomer and exciplex emissions and is the most difficult to resolve. A more typical, and trivial example is shown in Figure 1. Table 3 gives the quantum yields of the charge-transfer emissions measured in heptane. In all cases $\Phi_{\mathrm{F}}^{\mathrm{CS}} \leq 0.15$, and we conclude fluorescence is a minor decay route for these species, as expected from their high degree of charge separation.

Table 3. Efficiencies $(\phi)$, quantum yields $(\Phi)$, and rate constants $(k)$ of fluorescence, intersystem crossing, product formation, and charge recombination in $n$-heptane.

\begin{tabular}{llllllllll}
\hline & {$[\mathrm{FN}][\mathrm{mm}]$} & $\phi_{\mathrm{F}}^{\mathrm{CS}}$ & $\Phi_{\mathrm{F}}^{\mathrm{CS}}$ & $k_{\mathrm{F}}\left[\mathrm{s}^{-1}\right]$ & {$[\mathrm{FN}][\mathrm{mM}]$} & $\Phi_{\mathrm{T}}^{\mathrm{CS}}$ & $\Phi_{\mathrm{P}}^{\mathrm{CS}}$ & $\Phi_{\mathrm{CR}}^{\mathrm{CS}}$ & $k_{\mathrm{CR}}\left[\mathrm{s}^{-1}\right]$ \\
\hline $\mathrm{Pe}+\mathrm{FN}$ & 5.8 & 0.0580 & 0.153 & $1.3 \times 10^{7}$ & 5.8 & 0.05 & 0.00 & 0.80 & $7.0 \times 10^{7}$ \\
$\mathrm{Py}+\mathrm{FN}$ & 4.2 & 0.0985 & 0.102 & $5.7 \times 10^{6}$ & 4.2 & 0.06 & 0.00 & 0.84 & $4.7 \times 10^{7}$ \\
$\mathrm{~Np}+\mathrm{FN}$ & 6.0 & 0.0042 & 0.0044 & $4.7 \times 10^{5}$ & 5.9 & 0.00 & 0.00 & 0.996 & $1.1 \times 10^{8}$ \\
$p-\mathrm{X}+\mathrm{FN}$ & 4.4 & 0.0075 & 0.0085 & $1.7 \times 10^{6}$ & 6.0 & 0.08 & 0.11 & 0.80 & $1.6 \times 10^{8}$ \\
$o-\mathrm{X}+\mathrm{FN}$ & 6.0 & 0.0040 & 0.0061 & $1.2 \times 10^{6}$ & 5.3 & 0.10 & 0.08 & 0.81 & $1.6 \times 10^{8}$ \\
\hline
\end{tabular}

The formation of triplet states was investigated by using laser flash photolysis and photoacoustic calorimetry (PAC). We were unable to detect naphthalene triplet states in the presence of FN concentrations greater than $1 \mathrm{~mm}$. However, transient absorptions were observed with the $\mathrm{X} / \mathrm{FN}, \mathrm{Py} / \mathrm{FN}$ and Pe/FN systems, Figure 5. By using laser flash photolysis,

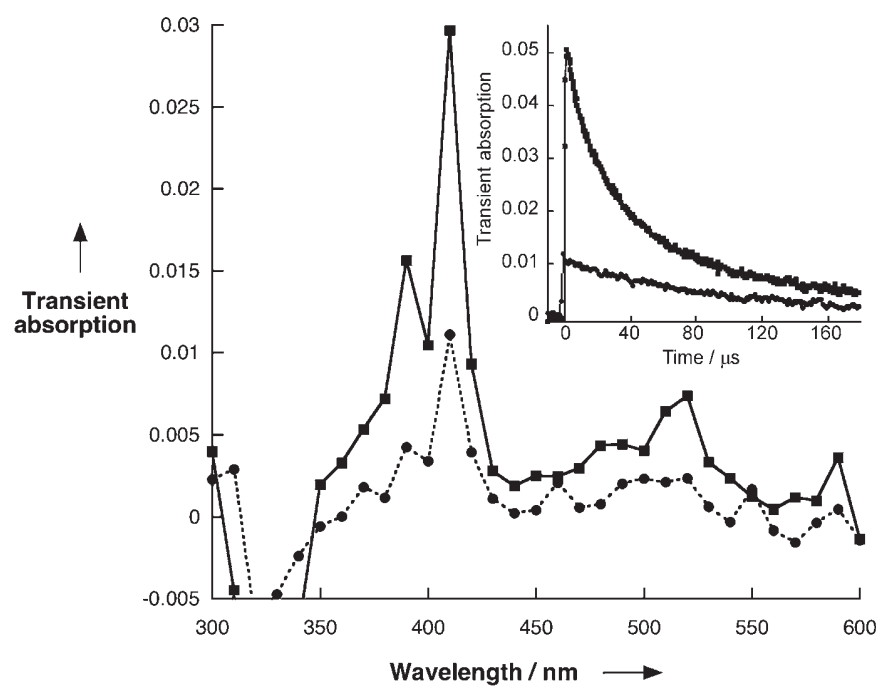

Figure 5. The triplet-triplet absorption spectra of pyrene in the absence (-) and presence (....) of fumaronitrile, in heptane. The inset shows triplet decays monitored at $\lambda=410 \mathrm{~nm}$. [pyrene] $\approx 0.1 \mathrm{~mm}$, [fumaronitrile] $=4.2 \mathrm{~mm}$.

we obtained the total triplet quantum yield $\left(\Phi_{\mathrm{T}}\right)$ of hydrocarbon/FN systems as the ratio of the triplet-state absorptions of hydrocarbon/FN versus pure hydrocarbon systems, for the same ground-state absorption, multiplied by the triplet quantum yield of the pure hydrocarbon. ${ }^{[31]}$ Both the unquenched hydrocarbon and the charge-separated species contribute to $\Phi_{\mathrm{T}}$. The contribution of the unquenched hydrocarbon was obtained from its intersystem-crossing rate 
and its lifetime in the presence of the experimental concentration of FN. This contribution was subtracted from $\Phi_{\mathrm{T}}$ and the triplet quantum yield from the charge-separated species $\left(\Phi_{\mathrm{T}}^{\mathrm{CS}}\right)$ was obtained, Table 3.

The importance of the nonradiative decay modes in the most exothermic systems was also evaluated in heptane by using PAC. Nonradiative decays lead to a transient heating of the solution that, in our PAC cell, is registered as an acoustic wave. ${ }^{[32,33]}$ The amplitude of the acoustic waves is related to the fraction of light energy $\left(f_{\mathrm{f}}\right)$ deposited as heat in the photoacoustic cell in the time window of the experiment. Figure 6 shows that the Np/FN system, in which the

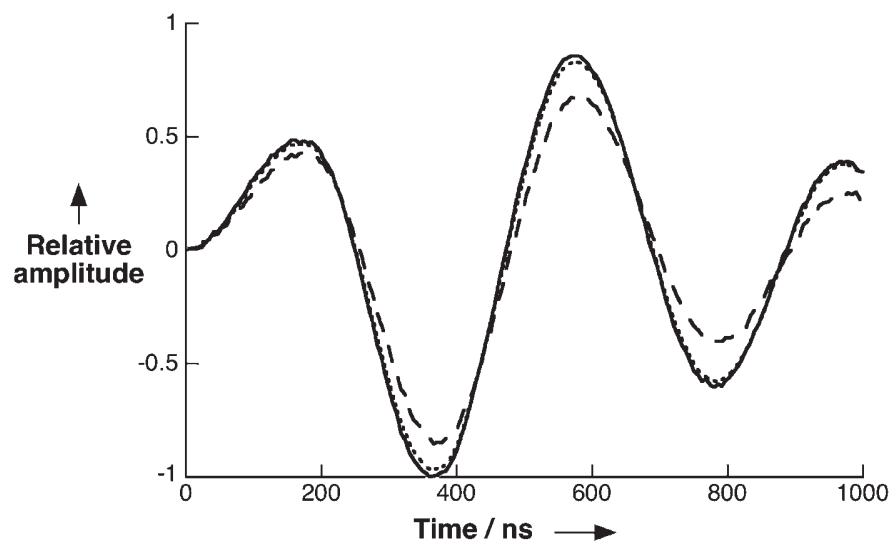

Figure 6. Normalised photoacoustic waves of 2-hydroxybenzophenone (photoacoustic reference....$), o$-xylene/fumaronitrile (---) and naphthalene/fumaronitrile $(-)$ in heptane, irradiated at $\lambda=266 \mathrm{~nm}$. [o-xylene] and [naphthalene] concentrations were adjusted to match the absorbance of 2-hydroxybenzophenone at the excitation wavelength $\left(\mathrm{A}_{266}=0.072\right)$, and [fumaronitrile] $=5.0$ and $5.7 \mathrm{~mm}$.

quenching of the hydrocarbon is nearly complete for the FN concentrations employed, releases as much energy as a PAC reference with a matched absorbance at the excitation wavelength, in less than $1 \mu \mathrm{s}$. This is consistent with the very low fluorescence and triplet quantum yields, and with the short lifetimes of naphthalene at the FN concentrations employed (3.84 ns) and of the charge-separated species (9.35 ns), measured by TCSPC. Figure 6 also shows that the $o$-X/FN system does not release all the absorbed energy as heat in the time window of the experiment.

The thermal energy released in the fast processes of the $o-\mathrm{X} / \mathrm{FN}$ system may have the following contributions [Eq. (3)] in which $E_{\mathrm{S}}, E_{\mathrm{T}}$ and $E_{\mathrm{P}}$ are the energies of the singlet state, of the triplet state, and of a possible photochemical product, respectively.

$$
\begin{aligned}
f_{\mathrm{f}} E_{h v}= & \left(E_{h v}-E_{\mathrm{S}}\right)+E_{\mathrm{S}} \Phi_{\mathrm{IC}}+\left(E_{\mathrm{S}}-E_{\mathrm{T}}\right) \Phi_{\mathrm{T}}+ \\
& E_{\mathrm{S}} \Phi_{\mathrm{CR}}+\left(E_{\mathrm{S}}-E_{\mathrm{P}}\right) \Phi_{\mathrm{P}}
\end{aligned}
$$

This fraction was obtained by deconvolution of the $o-\mathrm{X}$ and reference PAC waves, ${ }^{[32,33]}$ and we obtained $f_{\mathrm{f}}=0.83$. The fraction of light energy lost radiatively by the singlet state and by the exciplex can be obtained from their fluorescence quantum yields and energies, and amounts to 0.02 . Therefore, the energy associated with the decays of the slow processes that are not measured by the acoustic waves is given by Equation (4) in which the contribution of the triplet is given by the total triplet quantum yield measured by flash photolysis, $\Phi_{\mathrm{T}}=0.13$, and $E_{\mathrm{T}}=82 \mathrm{kcal} \mathrm{mol}^{-1}$.

$f_{\mathrm{S}} E_{h v}=E_{\mathrm{T}} \Phi_{\mathrm{T}}+E_{\mathrm{P}} \Phi_{\mathrm{P}}=16 \mathrm{kcal} \mathrm{mol}^{-1}$

The remaining energy, $5 \mathrm{kcalmol}^{-1}$, is stored by other long-lived species. Assuming that the dimethyl derivative of Dewar benzene is formed and that its enthalpy of formation is $62 \mathrm{kcal} \mathrm{mol}^{-1}$ higher than that of xylene, as in the hexamethyl derivative, ${ }^{[34,35]}$ we obtain $\Phi_{\mathrm{P}}=0.08$. This value is reported as $\Phi_{\mathrm{P}}^{\mathrm{CS}}$ in Table 3, assuming that the same proportion of products comes from singlet and charge-separated states. The values of $\Phi_{\mathrm{CR}}^{\mathrm{CS}}$ can now be calculated because the quantum yields of all the other processes originated from the charge-separated state have been determined. These values of $\Phi_{\mathrm{CR}}^{\mathrm{CS}}$ together with the lifetimes given in Table 2 give the $\mathrm{CR}$ rates reported in Table 3.

In summary, the radiative, intersystem-crossing, and reactive pathways are minor contributors to the decay of the charge-separated species measured in heptane, in which charge-recombination quantum yields exceed 0.8. The separation between the monomer and exciplex emission maxima is larger in $\mathrm{scCO}_{2}$ than in heptane, and the charge-recombination pathway must be even more important in this solvent. Therefore, the lifetimes of the charge-separated species in $\mathrm{scCO}_{2}$ reflect almost quantitatively their CR rates.

It should be emphasised that successful measurements of $\mathrm{CR}$ rates depend on the delicate balance between the extent of charge transfer in weakly polar solvents and measurable exciplex fluorescence. The CR rates measured in this work are in good agreement with those reported for phenanthrene/FN $\left(4.8 \times 10^{7} \mathrm{~s}^{-1}\right),{ }^{[9]}$ phenanthrene/dimethyl fumarate $\left(6.9 \times 10^{8} \mathrm{~s}^{-1}\right),{ }^{[10]}$ trans-stilbene/FN $\left(6.3 \times 10^{7} \mathrm{~s}^{-1}\right)$, and transstilbene/dimethyl fumarate $\left(4.7 \times 10^{8} \mathrm{~s}^{-1}\right)^{[11]}$ in benzene, in which CR was also established as the dominant decay pathway. Good consistency was also observed with the decay of the HMB/TCNE CRIP in cyclohexane $\left(\Delta G^{0}=-36.1 \mathrm{kcal}\right.$ $\mathrm{mol}^{-1}$ ), which gives a rate of $6.0 \times 10^{10} \mathrm{~s}^{-1} \cdot{ }^{[36]}$ We tested other nitriles as acceptors (acrylonitrile, methacrylonitrile, tetracyanoethylene), but the exciplex fluorescence and stability were insufficient for reliable lifetime measurements. Charge recombination between aromatic hydrocarbon donors and cyanoaromatic acceptors have also been studied in acetonitrile, in which the charge separation is complete, and their rates can be compared with the rates measured in this work. For example, the charge recombination of 2,6,9,10-tetracyanoanthracene (TCA) with alkylbenzene CRIP has the following CR rates: ${ }^{[37]} 6.3 \times 10^{9} \mathrm{~s}^{-1}$ for TCA/durene $\left(\Delta G^{0}=\right.$ $\left.-51.2 \mathrm{kcal} \mathrm{mol}^{-1}\right), 4.9 \times 10^{9} \mathrm{~s}^{-1}$ for TCA $/ 1,2,3,4$-tetramethylbenzene $\left(\Delta G^{0}=-52.6 \mathrm{kcal} \mathrm{mol}^{-1}\right)$, and $1.0 \times 10^{8} \mathrm{~s}^{-1}$ for TCA/ mesithylene. Additionally, the CR rate of Py/TCNE $\left(\Delta G^{0}=\right.$ $\left.-21.2 \mathrm{kcal} \mathrm{mol}^{-1}\right)$ is $3.4 \times 10^{12} \mathrm{~s}^{-1} \cdot{ }^{[38]}$ For CRIP in acetonitrile 
the reaction energy is accurately estimated as $\Delta G^{0}=$ $E_{\mathrm{D}}^{\mathrm{ox}}-E_{\mathrm{A}}^{\text {red }} \cdot{ }^{39]}$

\section{Discussion}

Figure 7 plots the $\mathrm{CR}$ rate constants $\left(k_{\mathrm{CR}}\right)$ measured in this work as a function of the reaction energy. This figure also includes the HMB/TCNE system measured by Kimura and

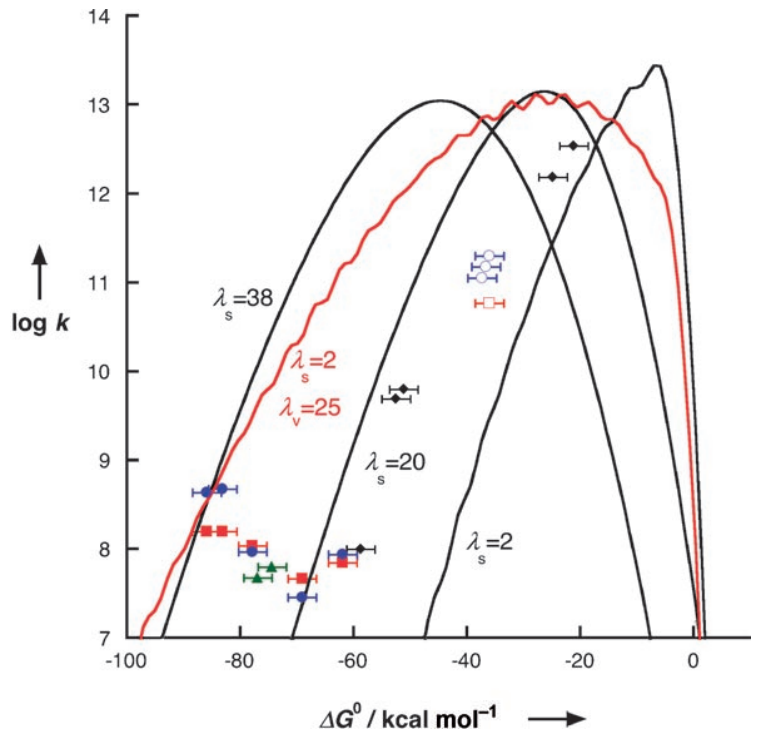

Figure 7. Charge recombinations in supercritical $\mathrm{CO}_{2}$ (blue circles), heptane (red squares), benzene (green triangles) and acetonitrile (black diamonds). The solid circles and squares represent the data measured in this work. The other points represent charge recombinations between aromatic hydrocarbon radical cations and the radical anions of FN, TCNE and TCA, referred to in the text. The black lines are golden rule calculations with $V=300 \mathrm{~cm}^{-1}, \hbar \omega_{v}=1500 \mathrm{~cm}^{-1}, \lambda_{\mathrm{v}}=5 \mathrm{kcal} \mathrm{mol}^{-1}$, and the solvent reorganisation energies indicated in the plot, in $\mathrm{kcal} \mathrm{mol}^{-1}$, and the red line are from similar calculations with $\lambda_{\mathrm{v}}=25$ and $\lambda_{\mathrm{s}}=2 \mathrm{kcal} \mathrm{mol}^{-1}$.

co-workers in comparable supercritical conditions, ${ }^{[40]}$ and the rates measured in benzene, cyclohexane, and acetonitrile for the CR with FN and TCNE mentioned above, by using $E_{\mathrm{A}}^{\mathrm{red}}=0.24 \mathrm{eV}$ for TCNE. ${ }^{[41]}$ Although the decay of the charge-separated species should be deep in the inverted region, their $k_{\mathrm{CR}}$ values are only weakly dependent on the driving force of the reaction. For example, the lifetimes of $\mathrm{Pe} / \mathrm{FN}$ and $o-\mathrm{X} / \mathrm{FN}$ exciplexes in heptane $\left(\Delta G_{\mathrm{CR}}^{0}=-62\right.$ and $-86 \mathrm{kcal} \mathrm{mol}^{-1}$ respectively) differ by a factor of two only.

As mentioned in the Introduction, the mild dependence of $k_{\mathrm{CR}}$ on $\Delta G^{0}$ has been observed before, and led Mataga to propose a solvent-independent model for CR. ${ }^{[12,13,42,43]}$ This model regards charge recombinations as radiationless transitions in the weak-coupling limit, with an overwhelming contribution from the high-frequency quantum modes $\left(\lambda_{\mathrm{v}}\right)$ and only a minor contribution from the solvent modes $\left(\lambda_{\mathrm{s}}\right)$, due to the tight structure of the CRIP. According to this model, the driving-force dependence of the $\mathrm{CR}$ rates is $k_{\mathrm{CR}} \approx \alpha \exp$ $\left(-\beta\left|\Delta G^{0}\right|\right)$, in which $\alpha$ and $\beta$ are constants independent of $\Delta G^{0}$. This model accommodates the solvent insensitivity of the $\mathrm{CR}$ rates described in the literature and apparent in Figure 7. The CR rates of TCA/mesithylene in acetonitrile, and $\mathrm{Pe} / \mathrm{FN}$ in $\mathrm{scCO}_{2}$ and in heptane all have $\Delta G^{0}=-61 \pm$ $1 \mathrm{kcal} \mathrm{mol}^{-1}$ and $k_{\mathrm{CR}}=(8.5 \pm 1.5) \times 10^{7} \mathrm{~s}^{-1}$. This supports the presentation of different solvents in the same free-energy relationship for CR. Asahi and Mataga proposed that the separation of the minima representing charge-separated and ground states increases with $\left|\Delta G^{0}\right|,{ }^{[12,13]}$ which is equivalent to an increase in the reorganisation energy with $\left|\Delta G^{0}\right|$. However, they modelled the CR rates from the energy-gap law of radiationless transitions that cannot reproduce the "double-inverted region" clearly observed in $\mathrm{scCO}_{2}$.

Gould and Farid reconciled the nonadiabatic theories with the shallow inverted region observed in CRIP, assuming that $\lambda_{\mathrm{s}}$ increases with the driving force of the reaction. ${ }^{[14]}$ According to the golden rule of quantum mechanics, the electron-transfer (ET) rate constant is written as the product of an electronic coupling $(V)$ and a Franck-Condon factor (FC) [Eqs. (5) and (6)]..$^{44-46]}$

$$
\begin{aligned}
& k=\frac{2 \pi}{\hbar}|V|^{2}(\mathrm{FC}) \\
& (\mathrm{FC})=\frac{1}{\sqrt{4 \pi \lambda_{\mathrm{s}} k_{\mathrm{B}} T}} \sum_{n=0}^{\infty} e^{-S} \frac{S^{n}}{n !} \exp \left[-\frac{\left(\Delta G^{0}+\lambda_{S}+n \hbar \omega_{v}\right)^{2}}{4 \lambda_{S} k_{\mathrm{B}} T}\right]
\end{aligned}
$$

In these equations the donor and acceptor are represented by one single high frequency $\left(\omega_{v}=\omega_{\mathrm{D}}=\omega_{\mathrm{A}}\right)$ and $S=\frac{\lambda_{v}}{\hbar \omega_{v}}$. The low-frequency contribution is usually estimated by using the dielectric continuum approximation formulated by Marcus [Eq. (7)] $]^{[47]}$ in which $r_{+}$and $r_{-}$are the effective radii of the two radical ions and $r$ is the distance between their centres.

$\lambda_{S}=e^{2}\left(\frac{1}{2 r_{+}}+\frac{1}{2 r_{-}}-\frac{1}{r}\right)\left(\frac{1}{n^{2}}-\frac{1}{\varepsilon}\right)$

According to the Connolly surfaces described above, we have $r_{+}=3.7 \AA$ for pyrene and $r_{-}=2.8 \AA$ for fumaronitrile; these values can be used with the solvent parameters of Equation (7) to obtain $\lambda_{\mathrm{s}}$ (heptane) $=0.02$ and $\lambda_{\mathrm{s}}\left(\mathrm{scCO}_{2}\right)=$ $2 \mathrm{kcal} \mathrm{mol}^{-1}$. The high-frequency contribution is often estimated with the equation proposed by Sutin, $\lambda_{\mathrm{v}}=$ $1 / 2 \Sigma_{i} \hbar_{i} \omega_{i} \Delta_{i}^{2}{ }^{[48]}$ in which the normal mode displacement $\Delta_{i}$ is calculated as the difference between the equilibrium bond lengths in the reactant and product states. By using this model, calculations for the $\mathrm{TCNE}^{0 /-}$ and naphthalene ${ }^{0 /-}$ selfexchanges gave $\lambda_{\mathrm{v}}=3.3$ and $6.7 \mathrm{kcal} \mathrm{mol}^{-1}$, respectively. ${ }^{[49,50]}$

Golden rule calculations also require a value for the electronic coupling. Its value is related to the radiative rate constant given by Equation (8), ${ }^{[51]}$ in which $\tilde{\nu}_{\mathrm{av}}$ is the average frequency of the reduced spectrum. ${ }^{[18]}$

$k_{\mathrm{F}}=\frac{16 \pi^{3}}{3 \varepsilon_{0} h^{3} c^{3}} n^{3} \tilde{v}_{\mathrm{av}} \Delta \mu^{2} V^{2}$ 
We have shown that the emission of the charge-separated species detected in this work can be fitted with a Gaussian curve. In this case the average frequency is the frequency of the maximum emission. By using such frequencies in Equation (8), the dipole moments given in Table 1, and the radiative rates given in Table 3, we obtain $V=880,270,620$, and $580 \mathrm{~cm}^{-1}$ for $\mathrm{Py} / \mathrm{FN}, \mathrm{Np} / \mathrm{FN}, p-\mathrm{X} / \mathrm{FN}$, and $o-\mathrm{X} / \mathrm{FN}$, respectively, in heptane. This method to extract $V$ is open to criticism. For example, the analysis of the HMB/TCNE system by the same method gave $V=1255 \mathrm{~cm}^{-1},{ }^{[52]}$ but an alternative method gave $V=500 \mathrm{~cm}^{-1}$. ${ }^{[36]}$ These data support the treatment of the most exothermic reactions with the nonadiabatic theories, but also illustrate the difficulties in extracting $V$ from the analysis of the charge-transfer bands. The usual practice is to obtain $V$ from empirical fits to the observed free-energy dependence of ET rates, and values between 100 and $750 \mathrm{~cm}^{-1}$ have been obtained for similar CRIP. $^{[53,54]}$ In view of these values, we selected $V=300 \mathrm{~cm}^{-1}$ for our golden rule calculations and recognise that this may lead to a factor of ten uncertainty in the calculated rates.

Figure 7 illustrates golden rule calculations with $V=$ $300 \mathrm{~cm}^{-1}, \hbar \omega_{v}=1500 \mathrm{~cm}^{-1}, \lambda_{\mathrm{v}}=5 \mathrm{kcal} \mathrm{mol}^{-1}$, and $\lambda_{\mathrm{s}}\left(\mathrm{scCO}_{2}\right)=$ 2 or $20 \mathrm{kcalmol}^{-1}$. This last value fits the CR rate of the Py/ FN system, but it is one order of magnitude higher than expected from the dielectric continuum model. Moreover, Figure 7 shows that by using the parameters above, the most exothermic CR can only be fitted with $\lambda_{\mathrm{s}}=38 \mathrm{kcalmol}^{-1}$. The other parameters may be modified to offset the change in $\lambda_{\mathrm{s}}$. For example, following the suggestion of Mataga that $\lambda_{\mathrm{v}} \gg \lambda_{\mathrm{s}}{ }^{[55]}$ we reproduced the most exothermic CR rate with $\lambda_{\mathrm{s}}=2$ and $\lambda_{\mathrm{v}}=25 \mathrm{kcal} \mathrm{mol}^{-1}$. The compensation between low and high-frequency modes has also been noted in the classical Marcus theory, ${ }^{[15]}$ but the fact that the total reorganisation energy $\left(\lambda=\lambda_{\mathrm{s}}+\lambda_{\mathrm{v}}\right)$ must increase with $\Delta G^{0}$ is indicated by all these analyses.

It is simple to demonstrate that, within our reaction series, variations in molecular size, $\lambda_{\mathrm{v}}$ or $V$ cannot offset the increase of $\lambda$ with $\Delta G^{0}$. The decrease in size from Py to $o$-X increases $\lambda_{\mathrm{s}}\left(\mathrm{scCO}_{2}\right)$ from 2.09 to $2.17 \mathrm{kcal} \mathrm{mol}^{-1}$, and the $o$ $\mathrm{X} / \mathrm{FN} \mathrm{CR}$ rate given by Equations (5)-(7) increases from $1.3 \times 10^{-3}$ to $1.4 \times 10^{-3} \mathrm{~s}^{-1}$. This is a negligible change on a rate that is 11 orders of magnitude slower than the observed rate. Submolecular sizes for $o$-X are required to bring Equation (7) into agreement with the experiment. The absence of a size effect in CR rates was discussed in detail elsewhere. ${ }^{[33]}$ By using Sutin's equation, it was estimated that $\lambda_{\mathrm{v}}$ decreases from $6.70 \mathrm{kcal} \mathrm{mol}^{-1}$ in naphthalene to $6.11 \mathrm{kcal} \mathrm{mol}^{-1}$ in benzene ${ }^{[49,50]}$ that should lead to a decrease of the $o-\mathrm{X} / \mathrm{FN}$ $\mathrm{CR}$ rate, further accentuating its deviation from the experimental data. Finally, the observed increase in $k_{\mathrm{CR}}$ from Py/ FN to $o-\mathrm{X} / \mathrm{FN}$ would require that $V$ increases by a factor $10^{5}$, but the emission spectra suggest that the opposite trend is occurring. The fundamental question is whether we find a physically meaningful model that relates the increase in the reorganisation energy to the driving force of the reaction.

To the best of our knowledge, the first theoretical model to explain the increase in $\lambda$ with $\left|\Delta G^{0}\right|$ was the intersecting- state model (ISM). ${ }^{[56]}$ The basis for this effect was recently discussed in the framework of atom and proton transfer, ${ }^{[57-59]}$ and can be simply illustrated. Let us assume that the sum of bond extensions in an isothermic $\mathrm{A}+\mathrm{BC} \rightarrow \mathrm{AB}+\mathrm{C}$ reaction is $d_{0}$. As the exothermicity of an atom or proton transfer increases, the transition state occurs earlier in the entrance valley. The activated complex of a very exothermic reaction will have a $\mathrm{BC}$ bond that resembles more closely that of $\mathrm{BC}$ in equilibrium, but at the expense of a much larger extension of the $\mathrm{AB}$ bond. Assuming the conservation of the bond order in this process, the limit of an ultra-exothermic reaction is an activated complex with an insignificant $\mathrm{BC}$ bond extension and an infinite $\mathrm{AB}$ bond extension. The conservation of the bond order requires that sum of the configurational changes $(d)$ increases as shown in Figure 8. Trans-

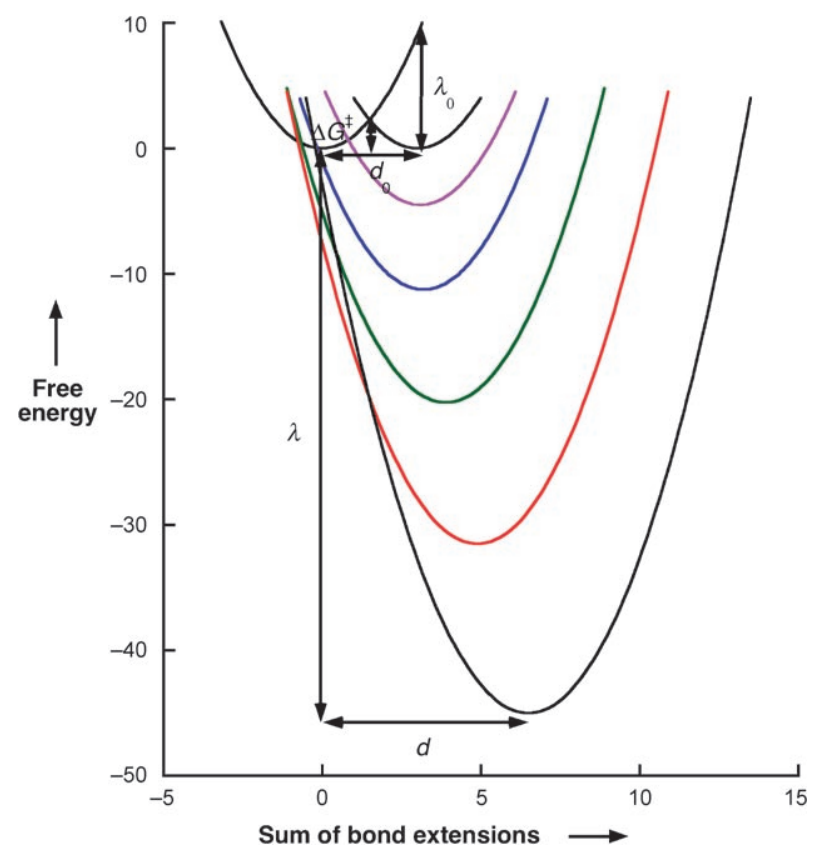

Figure 8. Reaction coordinate according to ISM. The sum of reactant and product bond extensions from equilibrium to transition state configurations $(d)$ increases with the exothermicity of the reactions $\left(\Delta G^{0}\right)$. This increase in $d$ leads to an increase in the total reorganisation energy $(\lambda)$. The activation energy $\left(\Delta G^{\ddagger}\right)$ first decreases with $\Delta G^{0}$, goes through a minimum (blue curve), increases in the inverted region (green curve), goes through a maximum (red curve), and decreases again in the doubleinverted region (red to black curves).

posing this principle to ET reactions, it was predicted that a "double-inverted region" should be observed for sufficiently exothermic reactions. ${ }^{[60]}$ This effect is not contemplated by the Marcus theory, because it assumes that the high-frequency contribution is proportional to the difference between the equilibrium bond lengths in the reactant and product states, and that difference is independent of the reaction energy.

According to ISM, the sum of bond extensions along the reaction coordinate can be obtained from the conservation of the bond orders as given in Equation $(9)^{[15,61]}$ in which $a^{\prime}$ 
is a constant $\left(a^{\prime}=0.156\right), n^{\neq}$is the transition-state bond order, $l_{\mathrm{r}}\left(l_{\mathrm{p}}\right)$ represents the bond length of the reactants (products) that participate in the reaction coordinate, and the parameter $\Lambda$ is associated with the dissipation of the reaction energy $\Delta G^{0}$.

$d=\frac{a^{\prime}}{2 n^{\ddagger}} \ln \left\{\frac{1+\exp \left(\sqrt{2 n^{\mp}} \Delta G^{0} / \Lambda\right)}{1-\left[1+\exp \left(\sqrt{2 n^{\mp}} \Delta G^{0} / \Lambda\right)\right]^{-1}}\right\}\left(l_{\mathrm{r}}+l_{\mathrm{p}}\right)$

As the bond orders remain constant in the course of outer-sphere ET reactions, $n^{\neq}$is approximately equal to the average of reactants and products bond orders. For example, TCNE has four triple bonds, four single bonds and one double bond, thus $n^{\neq}=2$, whereas benzene has $n^{\neq}=1.5$. The value employed in our calculations is the average of these two, $n^{\neq}=1.8$. The equilibrium bond lengths are also the average of the $\mathrm{C}-\mathrm{C}$ and $\mathrm{C}-\mathrm{N}$ bond lengths involved in the reaction coordinate, $l_{\mathrm{r}}+l_{\mathrm{p}}=2.7 \AA$. Thus, $\Lambda$ is the only parameter not determined a priori by ISM.

ISM and the nonadiabatic theories are not necessarily incommensurate. Both can be formulated as the product between an electronic (frequency) factor and a nuclear (Franck-Condon) factor. The frequency factor of Equations (5) and (6), $2 \pi / \hbar|V|^{2}\left(4 \pi \lambda_{\mathrm{S}} k_{\mathrm{B}} T\right)^{-1 / 2}$, gives $7 \times 10^{12} \mathrm{~s}^{-1}$ when $V=300 \mathrm{~cm}^{-1}$ and $\lambda_{\mathrm{s}}=20 \mathrm{kcal} \mathrm{mol}^{-1}$. The frequency factor of ISM is the product of the electronic frequency in an aromatic molecule $\left(v_{\mathrm{el}} \approx 10^{15} \mathrm{~s}^{-1}\right)$ by the electronic tunnelling probability through a square potential-energy barrier, $\chi_{\mathrm{r}}{ }^{\left[{ }^{[62,63]}\right.}$ The width of the tunnelling barrier is the donor-acceptor distance $(3.32 \AA)$ and its height $(\Phi)$ is the difference between the energy of the electron in the vacuum at rest and that in the highest occupied donor orbital. In the case of perylene, $\Phi \approx 2.71 \mathrm{eV},{ }^{[15,62,64]}$ and the frequency factor is $v=v_{\mathrm{el}} \chi_{\mathrm{r}}=4 \times 10^{12} \mathrm{~s}^{-1}$, which is very similar to that calculated by using the golden rule. For $o$-xylene, the higher electronic energy leads to $\Phi \approx 2.08 \mathrm{eV}$ and $\nu=8 \times 10^{12} \mathrm{~s}^{-1}$.

The activation energy of the nuclear factor is given by the crossing between the curves representing reactant and product states in Figure 8 [Eq. (10)] and requires values for $\Delta G^{0}$, $d$, and the force constants representing reactants and products $\left(f_{\mathrm{r}}, f_{\mathrm{p}}\right)$.

$\Delta G^{\neq}=\frac{1}{2} f_{\mathrm{r}} d_{\mathrm{r}}^{2}$

The force constants estimated from the frequency $\hbar \omega_{v}=$ $1500 \mathrm{~cm}^{-1}$ and the reduced mass of a CC oscillator are $f_{\mathrm{r}}=$ $f_{\mathrm{p}}=1.15 \times 10^{3} \mathrm{kcalmol}^{-1} \AA^{-2}$, very close to the average of those obtained by normal mode analysis of TCNE and naphthalene. ${ }^{[15]}$ Thus, the CR rates are given by Equation (11) and only involves one adjustable parameter, $\Lambda$.

$k_{\mathrm{ISM}}=v \exp \left(-\Delta G^{\neq} / R T\right)$

The results of ISM calculations are presented in Figure 9 for $v=8 \times 10^{12} \mathrm{~s}^{-1}$ and two values of $\Lambda$. The graphical ab-

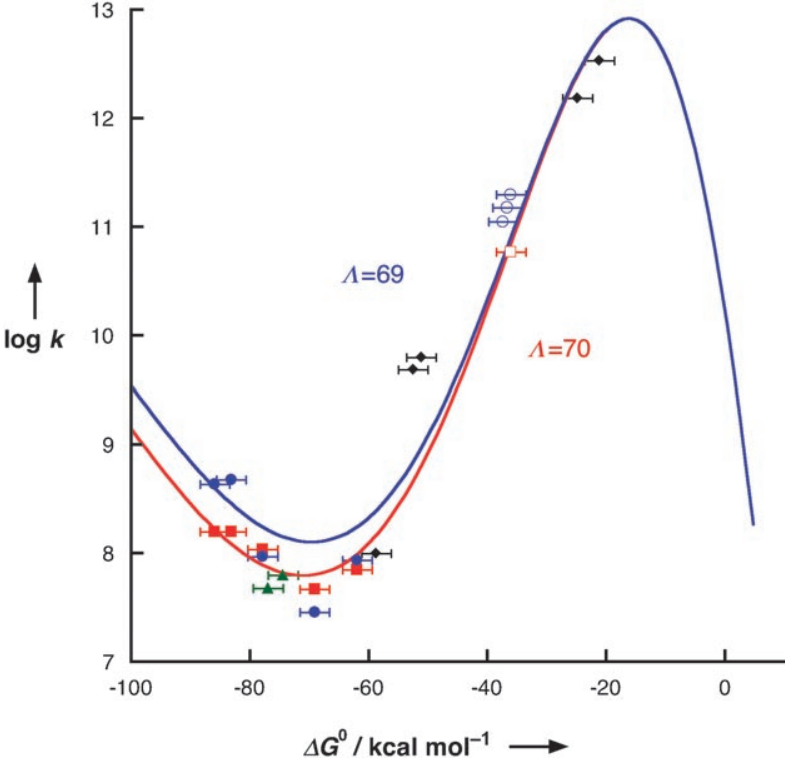

Figure 9. Charge recombinations in supercritical $\mathrm{CO}_{2}$ (blue circles), heptane (red squares), benzene (green triangles) and acetonitrile (black diamonds). The solid circles and squares represent the data measured in this work. The other points represent charge recombinations between aromatic hydrocarbon radical cations and the radical anions of FN, TCNE and TCA, referred to in the text. The lines are the thermal rates calculated with ISM with $n^{\neq}=1.8, l_{\mathrm{r}}+l_{\mathrm{p}}=2.7 \AA, f_{\mathrm{r}}=f_{\mathrm{p}}=1.15 \times 10^{3} \mathrm{kcal} \mathrm{mol}^{-1} \AA^{-2}$, $v=8 \times 10^{12} \mathrm{~s}^{-1}$, and the values of $\Lambda$ indicated in the plot, in $\mathrm{kcal} \mathrm{mol}^{-1}$.

stract presents calculations with electronic-energy-dependent frequency factors and $\Lambda=69.5 \mathrm{kcalmol}^{-1}$. In the normal region, the ET rates increase with an increase in exothermicity, but decrease with the increase in configurational changes $(d) ; \lambda$ (or $d$ ) increases rather modestly in this region, and the free-energy changes control the reactivity. In contrast, the inverted-region rates decrease with an increase in $\left|\Delta G^{0}\right|$ but increase with increasing $d$; the increase in $\lambda$ (or $d$ ) is now more significant and leads to the smooth freeenergy dependence observed. For sufficiently exothermic reactions, the increase in $\lambda$ (or $d$ ) starts to control the reactivity and the inverted region comes to an end.

The value of $\Lambda=69 \mathrm{kcal} \mathrm{mol}^{-1}$ corresponds to an increase in $\lambda$ by $17 \mathrm{kcalmol}^{-1}$ when $\Delta G^{0}$ decreases from -62 to $-86 \mathrm{kcalmol}^{-1}$. It is remarkable that both the ISM and the golden rule theories, as illustrated in Figure 7, give a similar increase in the reorganisation energy with the driving force of the reaction. The physical basis for this increase can be further explored with ISM.

The parameter $\Lambda$ is designated a "dynamic parameter" because it regulates the dissipation of $\Delta G^{0}$ by the accepting modes. ${ }^{[15]}$ This dissipation is associated with the coupling between the vibrational modes included in the reaction coordinate $(\mathrm{C}-\mathrm{C}$ and $\mathrm{C}-\mathrm{N}$ stretches) and nonreactive modes, such as low-frequency vibrations and solvent motion. ${ }^{[16]} \mathrm{A}$ better coupling promotes a better energy dissipation and is reflected by a higher value of $\Lambda$, which, in turn, leads to a smaller increase of the reorganisation energy with $\left|\Delta G^{0}\right|$. The relatively high value of $\Lambda$ required to reproduce the free-energy 
relationship of CR reactions suggests that the (high-frequency) ISM reaction coordinate modes are strongly coupled with another mode. The singularity of the CR reactions studied in this work is the presence of a hydrocarbon-nitrile stretching mode at $165 \mathrm{~cm}^{-1}$. Hochstrasser and co-workers discussed the redistribution of ET energy over various accepting modes and showed that the most populated ones are the high-frequency modes and donor-acceptor stretching mode. ${ }^{[38]}$ This corroborates the results of ISM calculations: the strong coupling with the $165 \mathrm{~cm}^{-1}$ mode helps to dissipate the reaction energy and leads to a large value of $\Lambda$. This is specific to $\mathrm{CR}$ reactions. For example, triplet-triplet energy transfer reactions do not have donor-acceptor stretching modes and, consequently, $\Lambda$ is smaller and a larger increase of $\lambda$ with $\left|\Delta G^{0}\right|$ takes place. $^{[16]}$

\section{Conclusion}

The quenching of the singlet state of aromatic hydrocarbons by fumaronitrile in supercritical carbon dioxide leads to essentially pure contact radical-ion pairs. The charge-recombination rate constants in CRIP provide compelling evidence that the reorganisation energies of ultra-exothermic ET reactions increase with $\left|\Delta G^{0}\right|$. The increase of $\lambda$ with $\left|\Delta G^{0}\right|$ limits the accuracy of cross-reaction schemes to predict the rates of exothermic reactions. Such an increase extends the linearity of free-energy relationships, and the quadratic dependence becomes more difficult to observe.

The linear free-energy relationship emphasised by Mataga and co-workers was observed until $\Delta G^{0}$ reached $-70 \mathrm{kcal} \mathrm{mol}^{-1}$. Then, the "inverted region" came to an end. The golden rule can only fit the experimental rates of very exothermic ET reactions with different reorganisation energies for each system. The most exothermic $\mathrm{CR}$ rates are faster than expected because of their increased reorganisation energy. ISM provides a rationale for the increase of the reorganisation energy with the reaction exothermicity. The free-energy relationship observed for charge recombinations in $\mathrm{scCO}_{2}$ has the shape of a "double-inverted region".

\section{Experimental Section}

All the reactants and solvents were the best quality available from Aldrich, except for the $p$-xylene that was from Riedel-de Haën, and were purified according to standard procedures. $\mathrm{CO}_{2}$ gas (Airliquide, N48) was passed through an Alltech charcoal trap, a Matheson Tri-Gas oxygen-absorbing purifier (model 6410), and a HIP 20 micron filter, prior to being compressed (HIP pressure generator model 87-6-5) into the high-pressure cell.

High-pressure controlled-temperature cells were specifically built in our laboratory for these experiments. ${ }^{[65]}$ They were made in Kovar with four $0.50 \mathrm{~cm}$ thick sapphire windows. Each window was $0.90 \mathrm{~cm}$ in diameter and they were positioned to provide two perpendicular $1.0 \mathrm{~cm}$ optical paths. Each sapphire window was sealed against the Kovar body of the cell by using two indium wires on both sides of the window, partially embedded in circular cages drilled in the Kovar parts. Tight screwing of the windows compressed the indium wires between the Kovar parts and the sapphire window, and provided and excellent seal. This seal was tested up to $30 \mathrm{MPa}$ and also performed well under high vacuum. The temperature control was achieved by drilling channels all around the cell and connecting them to a Julabo (model F-30C) thermostatic bath with external water circulation; the temperature was measured directly in the cell body. The high-pressure cells had two external connections through $1 / 16^{\text {" }}$ stainless steel tubes. One of them was connected though a valve to the high-pressure line and the other to a digital pressure indicator (OMEGA DP20 and Schaevitz pressure sensor, precision $\pm 0.25 \%$ ).

In a typical experiment, a few microliters of a concentrated solution of the desired product in ethyl ether was injected into the cell that was then connected to the pressure line, was evacuated for at least $30 \mathrm{~min}$, and was then pressurised with $\mathrm{CO}_{2}$. For highly volatile compounds such as benzene, naphthalene, or fumaronitrile, the vacuum was achieved at $170 \mathrm{~K}$ for as much as $1.5 \mathrm{~h}$ to avoid evaporation or sublimation. Our cells could be cooled to such low temperatures because they were exclusively made of Kovar, sapphire, and indium. We chose Kovar for the cell body because the thermal expansion of this alloy matches that of sapphire, and thermal amplitudes of 200 degrees did not cause any leaks.

Absorption and luminescence spectra were recorded with Shimadzu UV2100 and SPEX Fluoromax 3.22 spectrophotometers, respectively. Flash photolysis experiments were carried out on an Applied Photophysics LKS.60 laser-flash-photolysis spectrometer, with a Spectra-Physics Quanta-Ray GCR-130 Nd/YAG laser and a Hewlett-Packard Infinium Oscilloscope. Home-made equipment was used in single-photon counting and photoacoustic calorimetry measurements.

Fluorescence lifetimes were measured with a previously described homebuilt apparatus by using an IBH5000 coaxial flashlamp, filled with $\mathrm{N}_{2}$, $\mathrm{D}_{2}$, or $\mathrm{H}_{2}$ gases (or mixtures of them), or an IBH nanoLED (281, 339, $373 \mathrm{~nm}$ ), as excitation source, Philips XP2020Q photomultiplier, with excitation and emission wavelengths selected with Jobin-Ivon H20 monochromators, and a Canberra Instruments time-to-amplitude converter and multichannel analyser. ${ }^{[66]}$ Alternate measurements (1000 counts per cycle at the maximum) of the pulse profile and the sample emission were performed until $5 \times 10^{3}$ counts at the maximum were reached. The fluorescence decays were analysed by using Striker's method of modulating functions, with automatic correction for the photomultiplier "wavelength shift".

Time-resolved photoacoustic calorimetry (PAC) measurements were made with a front-face cell using a dielectric mirror that allows for a minimum background and maximum sensitivity of these measurements. ${ }^{[32,33]}$ In short, the sample, reference solutions and the solvent, were flowed separately with a $1 \mathrm{~mL} \mathrm{~min}^{-1}$ rate (SSI chromatographic pump) through a $0.11 \mathrm{~mm}$ thick cell. They were irradiated at $266 \mathrm{~nm}$ with the Nd/YAG laser at a frequency of $2 \mathrm{~Hz}$. A small fraction of the laser beam was reflected to a photodiode, used to trigger the transient recorder (Tektronix DSA 601, $1 \mathrm{Gss}^{-1}$ ). The photoacoustic waves, detected with a $2.25 \mathrm{MHz}$ Panametrics transducer (model 5676) and captured by the transient recorder, were transferred to a PC for data analysis. In a typical PAC experiment, 100 waves of the sample, reference, and pure solvent were recorded and averaged under the same experimental conditions. Four sets of averaged sample, reference, and solvent waves were used for the data analysis at a given laser intensity, and four laser intensities were employed in each experiment. The different laser intensities were obtained by interposing neutral density filters with transmissions between $25 \%$ and $100 \%$. All the measurements were made in heptane by using 2-hydroxybenzophenone as photoacoustic reference.

\section{Acknowledgements}

We thank Fundação para a Ciência e Tecnologia (Portugal) and FEDER (European Union) for financial support; project no. POCTI/QUI/47267/ 2002. C.S. acknowledges the Fundação para a Ciência e Tecnologia (Portugal) for grant SFRH/BPD/13297/2003. 
[1] L. G. Arnaut, J. Photochem. Photobiol. A 1994, 82, vii.

[2] N. Mataga, H. Miyasaka, Adv. Chem. Phys. 1999, 107, 431.

[3] P. Wang, B. Wenger, R. Humphry-Baker, J. E. Moser, J. Teuscher, W. Kantlehner, J. Mezger, E. V. Stoyanov, S. M. Zakeeruddin, M. Gratzel, J. Am. Chem. Soc. 2005, 127, 6850.

[4] D. I. Schuster, P. Cheng, P. D. Jarowski, D. M. Guldi, C. Luo, L. Echegoyen, S. Pyo, A. R. Holzwarth, S. E. Braslavsky, R. M. Williams, G. Klihm, J. Am. Chem. Soc. 2004, 126, 7257.

[5] J. P. Choi, K. T. Wong, Y. M. Chen, J. K. Yu, P. T. Chou, A. J. Bard, J. Phys. Chem. B 2003, 107, 14407.

[6] R. A. Marcus, Discuss Faraday Soc. 1960, 29, 21.

[7] E. S. Pysh, N. C. Yang, J. Am. Chem. Soc. 1963, 85, 2124.

[8] J. P. Petrovich, M. M. Baizer, M. R. Ort, J. Electrochem. Soc. 1969, 116, 743 .

[9] D. Creed, P. H. Wine, R. A. Caldwell, L. A. Melton, J. Am. Chem. Soc. 1976, 98, 621.

[10] R. A. Caldwell, D. Creed, J. Am. Chem. Soc. 1979, 101, 6960.

[11] F. D. Lewis, J. T. Simpson, J. Phys. Chem. 1979, 83, 2015.

[12] T. Asahi, N. Mataga, J. Phys. Chem. 1989, 93, 6575.

[13] T. Asahi, M. Ohkohchi, N. Mataga, J. Phys. Chem. 1993, 97, 13132.

[14] I. R. Gould, D. Noukakis, L. Gomez-Jahn, J. L. Goodman, S. Farid, J. Am. Chem. Soc. 1993, 115, 4405.

[15] S. J. Formosinho, L. G. Arnaut, R. Fausto, Prog. React. Kinet. 1998, $23,1$.

[16] C. Serpa, L. G. Arnaut, S. J. Formosinho, K. R. Naqvi, Photochem. Photobiol. Sci. 2003, 2, 616.

[17] M. Dossot, X. Allonas, P. Jacques, Chem. Eur. J. 2005, 11, 1763.

[18] I. R. Gould, R. H. Young, L. J. Mueller, A. C. Albrecht, S. Farid, J. Am. Chem. Soc. 1994, 116, 8188.

[19] E. Lippert, Z. Naturforsch. A 1955, 10, 541.

[20] N. Mataga, Y. Kaifu, M. Koizumi, Bull. Chem. Soc. Jpn. 1955, 28, 690.

[21] I. Ikemoto, H. Kuroda, Acta Crystallogr. B 1968, 24, 383.

[22] F. K. Larsen, R. G. Little, P. Coppens, Acta Crystallogr. B 1975, 31, 430.

[23] H. Beens, H. Knibbe, A. Weller, J. Chem. Phys. 1967, 47, 1183.

[24] X.-Y. Li, C.-X. Hu, J. Comput. Chem. 2002, 23, 874.

[25] M. L. Connolly, Science 1983, 221, 709.

[26] M. L. Connolly, J. Am. Chem. Soc. 1985, 107, 1118

[27] A. Weller, Z. Phys. Chem. 1982, 133, 93.

[28] B. R. Arnold, S. Farid, J. L. Goodman, I. R. Gould, J. Am. Chem. Soc. 1996, 118, 5482.

[29] J. Dresner, R. Kojer, J. Prochorow, I. Deperasinska, J. Lumin. 1997, $71,157$.

[30] Y. Kimura, Y. Takebayashi, N. Hirota, J. Chem. Phys. 1998, 108, 1485 .

[31] S. L. Murov, I. Carmichael, G. L. Hug, Handbook of Photochemistry, 2nd ed., Marcel Dekker, New York, 1993.

[32] L. G. Arnaut, R. A. Caldwell, J. E. Elbert, L. A. Melton, Rev. Sci. Instrum. 1992, 63, 5381.

[33] C. Serpa, L. G. Arnaut, J. Phys. Chem. A 2000, 104, 11075.

[34] W. Schäfer, Angew. Chem. 1966, 78, 716; Angew. Chem. Int. Ed. Engl. 1966, 5, 669.

[35] S. Kiau, G. Liu, D. Shukla, J. P. Dinnocenzo, R. H. Young, S. Farid, J. Phys. Chem. A 2003, 107, 3625
[36] K. Wynne, C. Galli, R. M. Hochstrasser, J. Chem. Phys. 1994, 100, 4797.

[37] I. R. Gould, S. Farid, J. Phys. Chem. 1992, 96, 7635.

[38] K. Wynne, G. D. Reid, R. M. Hochstrasser, J. Chem. Phys. 1996 105, 2287.

[39] I. R. Gould, R. H. Young, R. E. Moody, S. Farid, J. Phys. Chem. 1991, 95, 2068

[40] K. Kimura, Y. Takebayashi, N. Hirota, Chem. Phys. Lett. 1996, 257, 429.

[41] D. Rehm, A. Weller, Isr. J. Chem. 1970, 8, 259.

[42] A. Osuka, G. Noya, S. Taniguchi, T. Okada, Y. Nishimura, I. Yamazaki, N. Mataga, Chem. Eur. J. 2000, 6, 33.

[43] N. Mataga, H. Chosrowjan, S. Taniguchi, Y. Shibata, N. Yoshida, A. Osuka, T. Kikuzawa, T. Okada, J. Phys. Chem. A 2002, 106, 12191.

[44] R. P. Van Duyne, S. F. Fischer, Chem. Phys. 1974, 5, 183.

[45] N. R. Kestner, J. Logan, J. Jortner, J. Phys. Chem. 1974, 78, 2148

[46] S. Efrima, M. Bixon, Chem. Phys. Lett. 1974, 25, 34

[47] R. A. Marcus, J. Chem. Phys. 1956, 24, 966.

[48] N. Sutin, Annu. Rev. Nucl. Sci. 1962, 12, 285.

[49] G. Grampp, W. Jaenicke, Ber. Bunsen-Ges. 1991, 95, 904

[50] S. Jakobsen, K. V. Mikkelsen, S. U. Pedersen, J. Phys. Chem. 1996 $100,7411$.

[51] I. R. Gould, D. Noukakis, L. Gomez-Jahn, R. H. Young, J. L. Goodman, S. Farid, Chem. Phys. 1993, 176, 439

[52] K. Kulinowski, I. R. Gould, A. B. Myers, J. Phys. Chem. 1995, 99, 9017.

[53] E. Vauthey, J. Phys. Chem. A 2001, 105, 340

[54] I. R. Gould, S. Farid, Acc. Chem. Res. 1996, 29, 522.

[55] H. Miyasaka, S. Kotani, A. Itaya, G. Schweitzer, F. C. De Schryver, N. Mataga, J. Phys. Chem. B 1997, 101, 7978.

[56] A. J. C. Varandas, S. J. Formosinho, J. Chem. Soc. Chem. Commun. 1986, 163.

[57] L. G. Arnaut, A. A. C. C. Pais, S. J. Formosinho, J. Mol. Struct. 2001, $563-564,1$.

[58] L. G. Arnaut, A. A. C. C. Pais, S. J. Formosinho, M. Barroso, J. Am. Chem. Soc. 2003, 125, 5236.

[59] M. Barroso, L. G. Arnaut, S. J. Formosinho, ChemPhysChem 2005, 6,363 .

[60] L. G. Arnaut, S. J. Formosinho, J. Mol. Struct. THEOCHEM 1991, 233, 209.

[61] A. J. C. Varandas, S. J. Formosinho, J. Chem. Soc. Faraday Trans. 2 1986, 82, 953 .

[62] S. J. Formosinho, L. G. Arnaut, Bull. Chem. Soc. Jpn. 1997, 70, 977.

[63] L. G. Arnaut, S. J. Formosinho, J. Photochem. Photobiol. A 1997, $111,111$.

[64] L. G. Arnaut, L. G. Formosinho, J. Photochem. Photobiol. A 1996, 100,15 .

[65] N. Chattopadhyay, C. Serpa, M. I. Silva, L. G. Arnaut, S. J. Formosinho, Chem. Phys. Lett. 2001, 347, 361.

[66] J. Seixas de Melo, P. F. Fernandes, J. Mol. Struct. 2001, 565-566, 69.

Received: June 24, 2005 Revised: December 13,2005 Published online: March 20, 2006 